\title{
Inhibition of Aquaporin 4 Decreases Amyloid A 340 Drainage Around Cerebral Vessels
}

\author{
Gabriela-Camelia Rosu ${ }^{1} \cdot$ Bogdan Catalin ${ }^{2,3} \cdot$ Tudor Adrian Balseanu ${ }^{2,3} \cdot$ Mogoanta Laurentiu $^{4}$. \\ Margaritescu Claudiu $^{5}$ • Samir Kumar-Singh ${ }^{6}$. Pirici Daniel ${ }^{1}$ (iD
}

Received: 18 February 2020 / Accepted: 24 July 2020 / Published online: 11 August 2020

(C) The Author(s) 2020

\begin{abstract}
Aquaporin-4 (AQP4) is located mainly in the astrocytic end-feet around cerebral blood vessels and regulates ion and water homeostasis in the brain. While deletion of AQP4 is shown to reduce amyloid- $\beta(A \beta)$ clearance and exacerbate A $\beta$ peptide accumulation in plaques and vessels of Alzheimer's disease mouse models, the mechanism and clearing pathways involved are debated. Here, we investigated how inhibiting the function of AQP4 in healthy male C57BL/6 J mice impacts clearance of A $\beta 40$, the more soluble $A \beta$ isoform. Using two-photon in vivo imaging and visualizing vessels with Sulfurodamine 101 (SR101), we first showed that $A \beta 40$ injected as $a \leq 0.5-\mu l$ volume in the cerebral cortex diffused rapidly in parenchyma and accumulated around blood vessels. In animals treated with the AQP4 inhibitor TGN-020, the perivascular A $\beta 40$ accumulation was significantly $(P<0.001)$ intensified by involving four times more vessels, thus suggesting a generalized clearance defect associated with vessels. Increasing the injecting volume to $\geq 0.5 \leq 1 \mu \mathrm{l}$ decreased the difference of $\mathrm{A} \beta 40$-positive vessels observed in nontreated and AQP4 inhibitor-treated animals, although the difference was still significant $(P=0.001)$, suggesting that larger injection volumes could overwhelm intramural vascular clearance mechanisms. While both small and large vessels accumulated $\mathrm{A} \beta 40$, for the $\leq 0.5$ - $\mu$ l volume group, the average diameter of the $\mathrm{A} \beta 40$-positive vessels tended to be larger in control animals compared with TGN-020-treated animals, although the difference was non-significant $(P=0.066)$. Using histopathology and ultrastructural microscopy, no vascular structural change was observed after a single massive dose of TGN-020. These data suggest that AQP4 deficiency is directly involved in impaired A $\beta$ brain clearance via the peri-/para-vascular routes, and AQP4mediated vascular clearance might counteract blood-brain barrier abnormalities and age-related vascular amyloidopathy.
\end{abstract}

Gabriela-Camelia Rosu and Bogdan Catalin contributed equally to this work.

Electronic supplementary material The online version of this article (https://doi.org/10.1007/s12035-020-02044-8) contains supplementary material, which is available to authorized users.

Bogdan Catalin

bogdan.catalin@umfcv.ro

Pirici Daniel

daniel.pirici@umfcv.ro

Gabriela-Camelia Rosu

nicola_camelia92@yahoo.com

Tudor Adrian Balseanu

adibalseanu@yahoo.com

Mogoanta Laurentiu

laurentiu_mogoanta@yahoo.com

Margaritescu Claudiu

c_margaritescu2000@yahoo.com

Samir Kumar-Singh

samir.kumar-singh@uantwerpen.be
1 Department of Research Methodology, University of Medicine and Pharmacy of Craiova, Petru Rares Street 2, 200349 Craiova, Dolj, Romania

2 Experimental Research Centre for Normal and Pathological Aging, University of Medicine and Pharmacy of Craiova, Craiova, Romania

3 Department of Physiology, University of Medicine and Pharmacy of Craiova, Petru Rares Street 2, 200349 Craiova, Dolj, Romania

4 Department of Histology, University of Medicine and Pharmacy of Craiova, Craiova, Romania

5 Department of Pathology, University of Medicine and Pharmacy of Craiova, Craiova, Romania

6 Faculty of Medical \& Health Sciences, Molecular Pathology Group, Laboratory of Cell Biology \& Histology, University of Antwerp, Antwerp, Belgium 
Keywords Aquaporin $4 \cdot$ Amyloid · TGN-020 · A $\beta 40 \cdot$ Perivascular drainage $\cdot$ Alzheimer's disease

\section{Introduction}

The histopathological hallmark of Alzheimer disease (AD) is represented by the accumulation of amyloid $\beta$-peptide $(A \beta)$ plaques and neurofibrillary tangles generated by abnormally phosphorylated tau protein in the cortex of patients and is significantly associated with neurovascular dysfunction and neuronal loss $[1,2]$. Genetic investigations have placed $A \beta$ upregulation, either as normal or as modified less soluble and more toxic isoforms, as a key factor in $\mathrm{AD}$ pathogenesis. Genetically determined AD is in fact rare [3, 4], and sporadic late onset cases (LOAD) account for the majority of patients, suggesting that an impaired $\mathrm{A} \beta$ degradation/clearance due to aging and less efficient catabolic/drainage pathways might be more central to the disease rather than $A \beta$ overproduction. While LOAD is classically seen as an end-of-life pathology, careful epidemiological analysis suggests that young and/or middle life exposer to certain risk factors, namely, activity and cardiovascular performance, poor diet with major emphasis on insulin resistance, and even depression, impacts patient outcome and might lead to an earlier onset of disease [5-7]. This raises more questions about the exact mechanism by which $\mathrm{A} \beta$ causes $\mathrm{AD}$ with several competing theories currently being researched, such as a direct toxicity of $A \beta$ and its isoforms [8-10], a pro-oxidative stress shift in the brain [11, 12], a direct receptor interference, and mitochondrial dysfunction - all leading to synaptic dysfunction and neuronal loss $[10,13,14]$. Interestingly, the soluble $(\mathrm{A} \beta 40)$ and insoluble $(\mathrm{A} \beta 42)$ fractions have been linked to different pathological events. While high levels of the soluble $A \beta$ isoform precipitate in the blood vessels walls as cerebral amyloid angiopathy (CAA) and directly contribute to the cognitive decline $[15,16], A \beta 42$ is the main component of the senile plaques found in AD [17]. Regardless of the cause, $A \beta$ production/clearance is still imbalanced in $\mathrm{AD}$ patients. With up to $50 \%$ of the $A \beta$ being cleared across the blood-brain barrier (BBB) [18], it seems that investigating the mechanism by which $A \beta$ is cleared needs a more careful consideration, especially in respect to $A \beta 40$ and $A \beta 42$ isoforms. In this respect, $A \beta 40$ is the major isoform shown to be cleared through and along vascular route (reviewed in [19]).

The most abundant water diffusion channel in the CNS is aquaporin 4 (AQP4), expressed mostly on the membranes of ependymal cells, perivascular and subpial astrocytes, and under normal circumstances; the expression is highly polarized to astrocytic end-feet which come in contact with the vascular basement membranes as part of the BBB [20]. The waterexchange around the BBB has been showed to be highly dependent on AQP4, both in normal and pathological conditions. Thus, AQP4 deletion in mice results in an almost one- third decrease of the brain water uptake in normal conditions [21], and inducing cytotoxic brain oedema with an intact BBB (like water intoxication and an ischemic stroke without hemorrhagic transformation) results in significantly decreased brain oedema compared with wild animals [22, 23]. As expected, vasogenic oedema, like in the case of intraparenchymal fluid infusion, cortical-freeze injury, brain tumors, brain abscess, and subarachnoid hemorrhages, on the other hand, leads to increased brain water retention in $\mathrm{AQP} 4^{-1}$ animals compared with their non-transgenic counterparts $[24,25]$. Not only AQP4 knock-out leads to reduced cytotoxic oedema after an ischemic event but also singular administration of the TGN-020 AQP4 inhibitor, both $30 \mathrm{~min}$ before and 15 min after the ischemia [26, 27]. We and others have showed that in ischemic conditions, like after a stroke with non-hemorrhagic transformation, AQP4 loses its polarization for the end-feet and becomes expressed all over the astrocytic membrane not noly in rats but also in humans [27-29].

Recently, with the viewpoint to elucidate the mechanisms of cerebral water exchange and interstitial fluid drainage in the brain $[27,30,31]$, AQP4 has been also putatively linked with $\mathrm{AD}[32,33]$. This is based on work done on transgenic animals overexpressing $A \beta$ and lacking AQP4 channel [34-36]. However, in these situations, $A \beta$ is pathologically overproduced that overwhelms clearance pathways [37]. To understand the role of AQP4 in perivascular clearance of $\mathrm{A} \beta$ under physiological conditions mimicking early prodromal stages of $\mathrm{AD}$, we evaluated here the drainage of soluble $\mathrm{A} \beta 40$ after a transient inhibition of AQP4.

\section{Materials and Methods}

\section{Animals and Treatment}

The study was performed on 26 male C57BL/6 $\mathrm{J}(N=8$ for ex vivo studies and $N=18$ for in vivo studies) mice aged 3 4 months [mean weight $25.5 \mathrm{~g}$; standard deviation (SD) $1.84 \mathrm{~g}]$. The animals were housed in a controlled $12 \mathrm{~h} / 12 \mathrm{~h}$ of light/dark cycle, with unlimited access to water and food. The night prior to the beginning of experiments, food was withdrawn from the cages. All experiments have been conducted following the Federation of European Laboratory Animal Science Associations (FELASA) guidelines and have been approved by the local Ethics Committee of the University of Medicine and Pharmacy of Craiova (no 91/ 13.09.2018), under the Romanian and European laws, in accordance with Helsinki ethical guidelines.

Given the fact that there is no study yet to address the effect of TGN- 020 as a function of its concentration, and all previous 
pilot studies available used maximal dosages, together with the fact that, to our knowledge, it has no histopathological or clinical side effects, for all experiments, a single massive dose of TGN-020 AQP4 inhibitor $(400 \mathrm{mg} / \mathrm{kg}$ ) was used, in order to saturate the AQP4 and identify any putative subtle changes across the brain-blood barrier. The TGN- 020 chloride salt [N-(1,3,4-thiadiazol-2-yl) pyridine-3-carboxamide dihydrochloride, $\mathrm{MW}=279.1463$ ] (Ukrorgsyntez Ltd., Kiev, Ukraine) was dissolved in $0.4 \mathrm{ml}$ sterile distillate water and titrated with $2 \mathrm{M} \mathrm{NaOH}$ to a $\mathrm{pH}$ of 8 . In order to induce, as much as possible, the same volumetric and osmotic changes in all animals, and given the untitered final concentration of the TGN-020 chloride salt as roughly $0.1 \mathrm{~mol} / \mathrm{l}$, control animals received $0.4 \mathrm{ml}$ of isotonic saline $(0.15 \mathrm{~mol} / \mathrm{l})$ [27]. At $30 \mathrm{~min}$ after the IP injections, animals designated to the ex vivo histopathology and EM arm of the study (TGN-020 N=5 and Control $N=3$ ) were anesthetized and perfused first with PBS $(5 \mathrm{~min})$ and then with a mixture of 3.4\% Neutral Buffered Formalin (NBF) and 3\% Glutaraldehyde, pH 7.2 (10 min), after which brains dissected. One hemisphere was kept in NBF (neutral buffered-formalin)/glutaraldehyde for EM analysis, and the other half was placed in $4 \% \mathrm{NBF}$ for $24 \mathrm{~h}$ and further processed for paraffin embedding and histopathology. The animals to be utilized for the in vivo analysis $(N=18)$ received the same IP regimens of TGN-020 salt or isotonic saline after experimental setup and stereotaxic fixation, at 30 min prior to the $A \beta$ injection.

\section{Amyloid Injection, Two-Photon Laser Scanning Microscopy, and Fluorescence Microscopy}

High-resolution, time-lapse in vivo imaging was performed using a 7MP Zeiss two-photon laser scanning microscope (2P-LSM) (Carl Zeiss MicroImaging GmbH, Jena, Germany) on anesthetized $(120 \mathrm{mg} / \mathrm{kg}$ ketamine and $12 \mathrm{mg} / \mathrm{kg}$ xylazine) C57BL/6J mice $(N=18)$. Prior to the imaging session, a cranial window was implanted, using a previously described method [38]. In summary, after the skin and soft tissue were removed, a custom-made handler was fixed to the right parietal skull of the animals using dental cement. A small craniotomy was performed, right over the somatosensory cortex. After any bleeding was stopped, a 20min 2P-LSM session was used as baseline. Before starting the imaging session, optimization was made by placing the animal on a special custom-made imaging table, capable of manual tilting the animal in $x$ and $y$ axes [39]. 2P-LSM imaging was performed in between 100 and $200 \mu \mathrm{m}$ under the surface, in Z-stack planes of $425.10 \times 425.10 \mu \mathrm{m}$, using a W-Plan Apochromat 20×/1.0 DIC Vis-IR water immersion objective (Carl Zeiss) controlled by ZEN 2010 imaging software (Carl Zeiss). The fluorophore was excited using an fs-pulsed titanium-sapphire laser (Chameleon Vision II, Coherent, Glasgow, UK) with a peak power of $3.5 \mathrm{~W}$ tuned to $910 \mathrm{~nm}$ [38]. Using a front filling technique, a glass pipet, with an opening of 15 $25 \mu \mathrm{m}$, was filled with either 0.5 or $1 \mu \mathrm{l}$ human amyloid- $\beta 1-$ 40 peptide (Hilyte Fluor 488 labelled, AnaSpec EGT, Fremont, CA, USA catalog number AS-60491-01), diluted as $0.5 \mathrm{mg} / \mathrm{ml}(100 \mu \mathrm{M}$ in $0.25 \% \mathrm{NH} 4 \mathrm{OH}$, and frozen at $-30{ }^{\circ} \mathrm{C}$ as $20 \mu \mathrm{l}$ aliquots) [40]. Before loading the pipet, thawed diluted aliquots were continuously mixed with a 20 - $\mu$ l pipette in order to break apart any preformed aggregates, and any remaining material was discarded. The pipette was inserted into the somatosensorial cortex utilizing a micromanipulator under transmission light microscopy settings and a $\times 5$ objective, taking special care to avoid piercing local blood vessels. The content of the pipette was slowly injected ( $\sim 1 \mathrm{~min}$ ) utilizing an injection pump, under microscope feedback for the $>0.5-\mu$ l group $(N=5$ controls and $N=5$ treated with TGN-020), while for the $<0.5-\mu l$ volume ( $N=4$ controls and $N=4$ treated with TGN-020), the pump was stopped and momentarily reversed immediately after the first puff was observed. This process utilized a custom-made 3D-printed and electronically controlled pump that advanced the piston of a 1- $\mu$ l Hamilton syringe [41]; the needle of the syringe was hydraulically connected with the injection pipette utilizing silicone gun oil and inextensible Teflon tubing. Sulfurodamine 101 (Merck KGaA, Darmstadt, Germany) was dissolved in saline to obtain a $100 \mu \mathrm{M}$ solution. To visualize blood vessels under the 2P-LSM, $0.2 \mathrm{ml}$ of the prepared solution was injected IP $5 \mathrm{~min}$ prior to the imaging sessions. Animals were kept under anesthesia, and for the following $40 \mathrm{~min}$, scanning sessions were initiated at each $5 \mathrm{~min}$. At the end of the experiment, animals were administrated one more anesthetic dose, then they were decapitated, brains removed, and cut as $30-\mu \mathrm{m}$ thick sections using a vibratome. Sections were collected on poly-L-lysine (PLL)-coated slides, fixed in $4 \% \mathrm{NBF}$ for $1 \mathrm{~min}$ and then a cover slipped with Vectashield H-1200 (Vector Laboratories, Peterborough, UK) mounting medium.

Conventional fluorescent images were grabbed with a $\times 10$ plan apochromat objective (NA $=0.30$ ), utilizing a Nikon Eclipse 90i motorized microscope (Nikon Instruments Europe BV, Amsterdam, The Netherlands) equipped with a Prior OptiScan ES111 motorized stage (Prior Scientific, Cambridge, UK), single-band fluorescence filters, a 16megapixel Nikon DS-Ri-2 CMOS cooled camera (Nikon), and driven by the Nikon NIS-Elements AR image analysis software.

\section{Fluorescence Microscopy and Post-fixation Basement Membrane Evaluation}

Brain hemispheres fixed in NBF were further processed for paraffin embedding, and $4-\mu \mathrm{m}$ thick sections were cut on a microtome and collected on PLL-coated slides. Besides classical hematoxylin-eosin staining, the tissue was processed for 
immunohistochemistry for visualizing endogenous immunoglobulins and vascular basement membranes (BM). For BM/ astrocyte visualization, the sections were first digested with proteinase $\mathrm{K}$ for $20 \mathrm{~min}$ at $37^{\circ} \mathrm{C}$ (Dako, Glostrup, Denmark), unspecific binding sites were blocked with $3 \%$ skimmed milk (Bio-Rad Laboratories GmbH, München, Germany), then the primary antibodies [rabbit-anti-laminin, 1:100 (Abcam, Cambridge, UK) and chicken anti-glial fibrillary acidic protein (GFAP), 1:500 (Novus Biologicals, Centennial, CO, USA)] were added together for $18 \mathrm{~h}$ at $4{ }^{\circ} \mathrm{C}$ and visualized with a mixture of goat anti-rabbit Alexa 596/goat anti-chicken Alexa 488 secondary antibodies (1:300, Thermo Fisher Scientific, Waltham, MA, USA) after 1-h incubation at room temperature. The slides were cover slipped with a DAPIcontaining mounting medium (Vectashield, H-1200, Vector Laboratories) and protected with nail polish. For endogenous mouse immunoglobulin visualization, the slides were blocked with 3\% skimmed milk, and then an anti-mouse horse-radish peroxidase (HRP)-labelled polymer was added on the slides for $1 \mathrm{~h}$ (goat anti-mouse HRP, Vector Laboratories). After thorough washing, the signal was visualized with Tyramide Alexa 488 diluted as 1:200 dilution in amplification medium, for $15 \mathrm{~min}$ (Thermo Fischer).

Slides were visualized, and random images were captured with the Nikon Eclipse 90i microscope utilizing a $\times 60$ plan apochromat immersion objective $(\mathrm{NA}=1.40)$. All images were saved in Nikon's proprietary format and processed first by a 5 -iteration blind deconvolution algorithm (NIS Elements AR), then for all blood vessels in each image, the thickness of the basement membranes was measured with a direct measuring tool in NIS-Elements. Only external (abluminal) basement membranes have been considered and measured in their thickest region. Perivascular spaces have not been considered, and vessels with unclear profiles were also not considered. Measurements have been averaged for each slide and then for each brain region of each animal.

\section{Electron Microscopy}

Designated brain hemispheres were fixed in the NBF/ Glutaraldehyde mixture, and then representative sections of grey matter were microdissected and processed for TEM according to MacGregor Sharp et al. [42]. Briefly, tissue blocks were trimmed and $80-\mathrm{nm}$ ultrathin sections cut using an Ultracut E microtome. Grids were examined using a Hitachi HT7700 transmission electron microscope operating a Morada G3 digital camera and Radius image capture software (EMSIS, Münster, Germany). Transmission electron microscopy (TEM) was performed by methodically scanning each sample from top right to bottom left. High-resolution low power images of 20 capillaries from the grey matter of each mouse (120 total) were digitally photographed.

\section{Data Analysis}

For the detailed analysis of in vivo $A \beta$ drainage and histopathology data, parameters like vessel positivity for $A \beta$, vessel diameters, $A \beta$ colocalization, and $B M$ thickness were determined by direct manual counting and measurements in ZEN 2010 and Image ProPlus 7 packages. For in vivo analysis and histopathology measurements, data were averaged first per animal, then per treatment group (treated/untreated), followed by statistical analysis. We defined a vessel as being $A \beta$ positive when either the red SR 101 signal colocalized with the green $A \beta$ or when there was an unambiguous compaction of green $A \beta$ signal directly on the vessel wall. A proof-of principle study was also conducted to assess if an image analysis algorithm might be able to accurately differentiate these vessels in our analysis (See Supplementary Material and Supplementary Fig. 1). All data were analyzed using GraphPadPrism 7 and Microsoft Excel. For statistical comparison of two groups, a Student $t$ test was used, while for multiple comparisons, we utilized a Tukey corrected twoway ANOVA. For EM images, Adobe Photoshop CS6 (Adobe Inc., San Jose, CA, USA) was used to perform a detailed analysis of capillary wall composition. Briefly, the endothelium, intramural cells, and basement membrane were segmented and analyzed for percentage surface area of the vessel wall using inbuilt Adobe Photoshop measure and analysis tools. Statistical analysis was performed using SPSS and univariate analysis of variance allowing for multiple comparisons (significance set at $P<0.05$ ). All figures display mean value and standard deviation of the means (SD). The statistical significance is displayed as follows: $*: P<0.05$, **: $P<0.01$, and $* * *: P<0.001$.

\section{Results}

\section{Vascular Intramural $A \beta$ Drainage Is Dependent on the Functionality of AQP4 Channels}

We first aimed to evaluate the diffusion and vascular intramural drainage of soluble $A \beta$ in the brain of the living animals. For this, we injected AlexaFluor488-labelled soluble fulllength $A \beta 40$ peptide into the superficial cortex of C57BL/6J mice and followed the injection site under the 2P-LSM for $45 \mathrm{~min}$. During the experiment, blood vessels were visible after systemic administration of SR 101. In vivo imaging confirmed that $A \beta 40$ rapidly diffused into the surrounding neuropil regardless of the injected volume $(<0.5 \mu \mathrm{l}$ or $>$ $0.5 \mu \mathrm{l})$. In all experiments, control animals displayed accumulation of $A \beta 40$ peptide around blood vessels near the injection site within the first minute of the injection, with some being visible for up to $40 \mathrm{~min}$ afterwards (Fig. 1 and Supplementary Fig. 2). After systemically injecting TGN-020 AQP4 inhibitor 

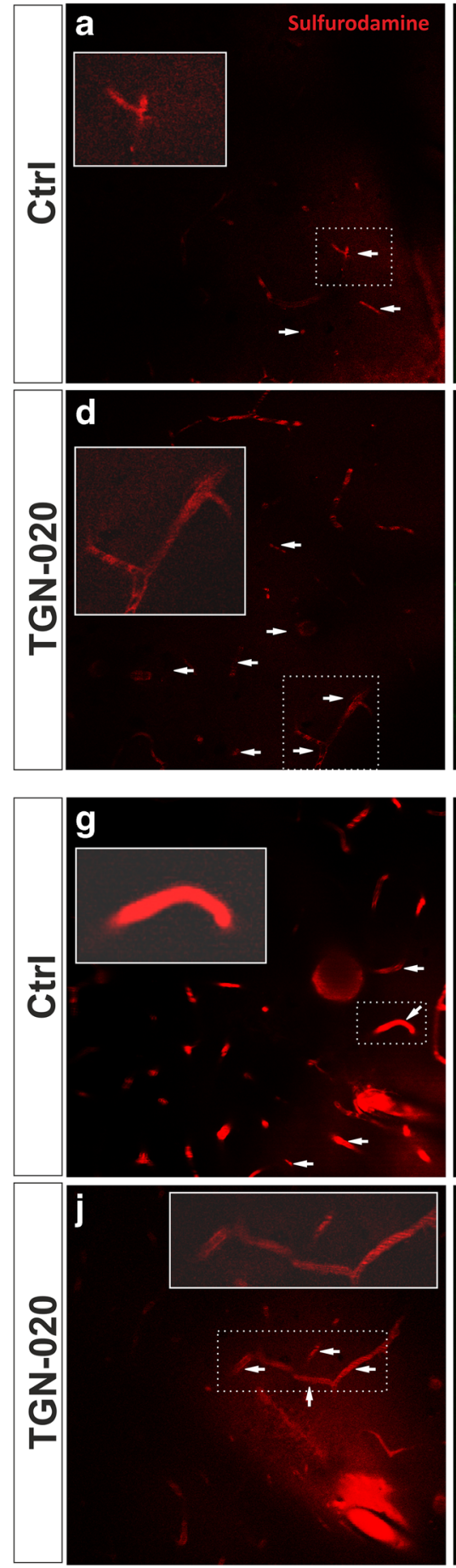

Fig. 1 Representative two-photon microscopy images of anesthetized mice, 10 min after $A \beta 40-A 488$ was injected in the upper layers of the right somatosensory cortex. Injecting a large volume floods the water drainage system, leading to some $A \beta 40$ deposits around blood vessels in control animals $(\mathbf{a}-\mathbf{c})$. The number of vessels surrounded by $A \beta 40$ is greater when blocking AQP4 function $(\mathbf{d}-\mathbf{f})$. Injecting small volumes of $A \beta 40$ leads to a limited number of vessels exhibiting $A \beta 40$ deposits in

prior to $A \beta 40$ injection, in vivo imaging clearly showed more vascular accumulation of $A \beta 40$ peptide compared with the control group, for both injected volumes (Fig. 1). A proof-of
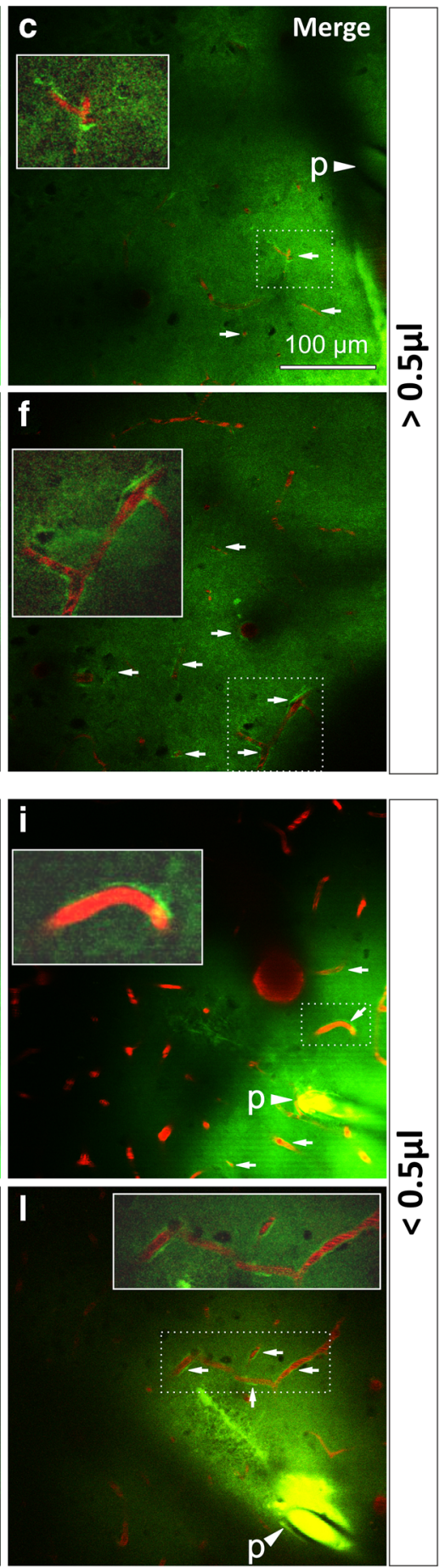

control animals $(\mathbf{g}-\mathbf{i})$; however, blocking AQP4 channels generates multiple $A \beta 40$ accumulation around vessels $(\mathbf{j}-\mathbf{I})$. In each image, insets represent magnified exemplary areas demonstrating abluminal $A \beta$ accumulation. Arrows point to regions of interest with clear-cut $A \beta 40$ being retained around the vascular lumens; arrow heads indicating a "p" denominate the position of the injection pipette tip, filled with the fluorescent $\mathrm{A} \beta 40$

principle analysis also revealed that the $A \beta 40$ signal densification in the close proximity of the vessels needed to deem the vessel positive can also be differentiated from negative vessels 
by an intensity-profile algorithm (Supplementary Fig. 1). Counting A $\beta 40$-positive vessels revealed that their number had almost increased four times for TGN-020-injected animals $(30.221 \pm 5.524 \%)$ for less than 0.5 - $\mu$ l injected volumes compared with controls $(7.946 \pm 4.458 \%)(P<0.001)$ (Fig. 2, a). Injecting a volume of more than $0.5 \mu \mathrm{l}$ drastically increased the number of vessels in both control animals $(20.393 \pm$ $5.857 \%)$ and the TGN-020-treated animals (33.475 \pm $9.624 \%)$, maintaining a significant difference between the control and treated animal groups $(P=0.001)$.

Next, we evaluated if the drainage of $A \beta$ occurs uniformly for vessels of all sizes. Measuring the diameter of the vessels showing $A \beta$ deposits, we showed that for the small volume injections, $A \beta$ accumulation was greater around smaller vessels in treated animals $(8.506 \pm 1.081 \mu \mathrm{m})$ compared with controls $(12.795 \pm 3.635 \mu \mathrm{m})$, although the difference did not attain statistical significance (Fig. 2, b, $P=0.066$ ). For the higher volume injections, the diameters were much more homogenous in treated animals $(6.550 \pm 1.571 \mu \mathrm{m})$ and controls (7.755 $\pm 2.629 ; P=0.896)$. For vessels not showing $\mathrm{A} \beta$ deposits around them, no difference between their average diameters for AQP4-treated $(5.563 \pm 0.632 \mu \mathrm{m})$ and control animals $(5.092 \pm 1.085 \mu \mathrm{m} ; P=0.27)$. During the course of the experiment, blood vessel diameter varied slightly over time $(P>0.05)$, probably as a direct result of pressure variations and pulsatility (Fig. 2, c).

Although the AQP4 inhibitor was given systemically, we further investigated if decreasing $A \beta$ concentration from the injection point influenced $A \beta$ disposition around vessels. Counting vessels as a function of distance from the tip of the injecting pipet, we were not able to identify any difference between control and AQP4 inhibitor group, with vessels depositing $\mathrm{A} \beta$ both near (within $20 \mu \mathrm{m}$ ) and distant to the injection site (at more than $360 \mu \mathrm{m}$ away from the tip) $(P=0.32)$.
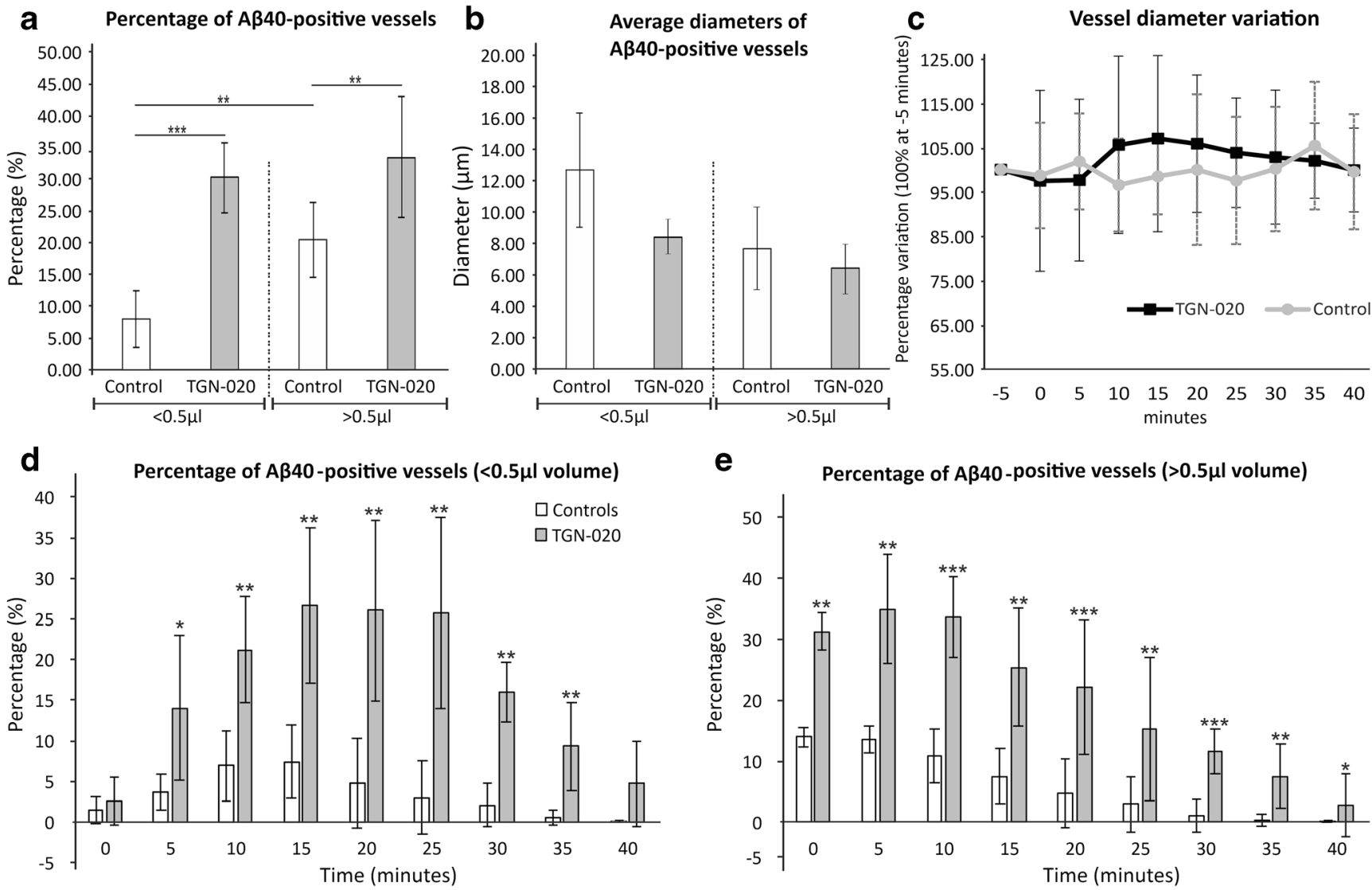

Fig. 2 Systemic administration of AQP4 inhibitor reveals a higher number of blood vessels showing $\mathrm{A} \beta 40$ deposits. a The total volume injected impacts the drainage system; however, regardless of the injected volume, blocking AQP4 channels leads to an increase frequency of $\mathrm{A} \beta 40$ deposits around vessels, compared with controls, predominantly for vessels (b) with a smaller diameter. c When analyzing the variation over time of the blood vessel diameters, no change could be observed. Investigating the dynamic of A $\beta 40$ drainage around the injected site, we could see differences for both small (d) and

large (e) injected volumes. The average number of elements per animal was considered for analysis in all instances. Mean $\pm \mathrm{SD} ;{ }^{*} P<0.05$, ${ }^{* *} P<0.01,{ }^{* * *} P<0.001 ; N=9$ control animals $(4$ for $<0.5 \mu 1 ; 5$ for $>0.5 \mu \mathrm{l}$ ) and $9 \mathrm{TGN}-020$ animals $(4$ for $<0.5 \mu \mathrm{l} ; 5$ for $>0.5 \mu \mathrm{l}$ ). For $\mathbf{a}$, an average of $n=51 \pm 9.16 / 43 \pm 11.83$ vessels have been considered for control group $(<0.5 \mu \mathrm{l} />0.5 \mu \mathrm{l})$, and respectively $n=46.83 \pm 9.57 / 53.83$ \pm 16.84 vessels have been considered for the TGN-020 group $(<0.5 \mu \mathrm{l} />$ $0.5 \mu \mathrm{l})$ 
Next, we studied the time dynamic of vascular $A \beta$ clearance by analyzing the persistence of the perivascular $A \beta$ around the injection site (Fig. 2, d, e). For the small injection volume, the percentage of positive vessels slowly increased for both TGN-020-treated and control animals over the first $15 \mathrm{~min}$, after which it plateaued for $10 \mathrm{~min}$, and then steeply decreased over the next $15 \mathrm{~min}$ when the experiments were stopped (Fig. 2, d). Between 5 and $35 \mathrm{~min}$, there was a significantly higher number of positive vessels for the treated group compared with the control animals $(P$, at least, $<0.05)$. For the higher volume injection, the number of positive vessels increased more rapidly and then slowly decreased until the end of the follow-up (Fig. 2, e). Here, basically, at every point of investigation, TGN-020-treated animals showed significantly more vessels accumulating $\mathrm{A} \beta(P$, at least, $<0.05)$.

\section{Ex Vivo Fluorescence Imaging Confirms the In Vivo Vascular Intramural A 340 Disposition}

On rapidly prepared vibratome cortical slices from the experimental animals, we could still identify fluorescent $A \beta 40$ and SR 101 in the blood vessels within 60 min after $A \beta$ injection (Fig. 3). In control animals, $A \beta 40$ could be identified mostly diffusing not only in the parenchyma but also in the walls of some larger penetrant blood vessels (Fig. 3, a-c). Compared with in vivo imaging, SR 101 was washed away from within the vascular lumens, however, still intimately coated the endothelia (Fig. 3, a, c, d, f). Accordingly, there was still a high degree of colocalization between $A \beta$ and SR 101 in the vessel walls. When comparing controls with TGN-020-treated animals, not only did blood vessels overall retained more $A \beta 40$ in their walls but in treated animals, we could also identify smaller diameter vessels retaining the dye, thus confirming the in vivo observation of significantly increased vascular intramural accumulation in AQP4 inhibitor-treated animals (Fig. 3, $\mathrm{d}-\mathrm{f}$ ). $A \beta$ signal that was still visible in the blood vessels walls showed a perfect colocalization with the remaining SR 101, at the level of clearly identifiable vessel walls folds.

\section{TGN-020-Treated Animals Show a Tendency for Reduced Vascular Permeability for Immunoglobulins}

We did not observe any gross morphological difference between the blood vessels of TGN-020-treated and control animals as visualized on the paraffin-embedded hemispheres, and where no acute bleedings or any inflammatory infiltrate
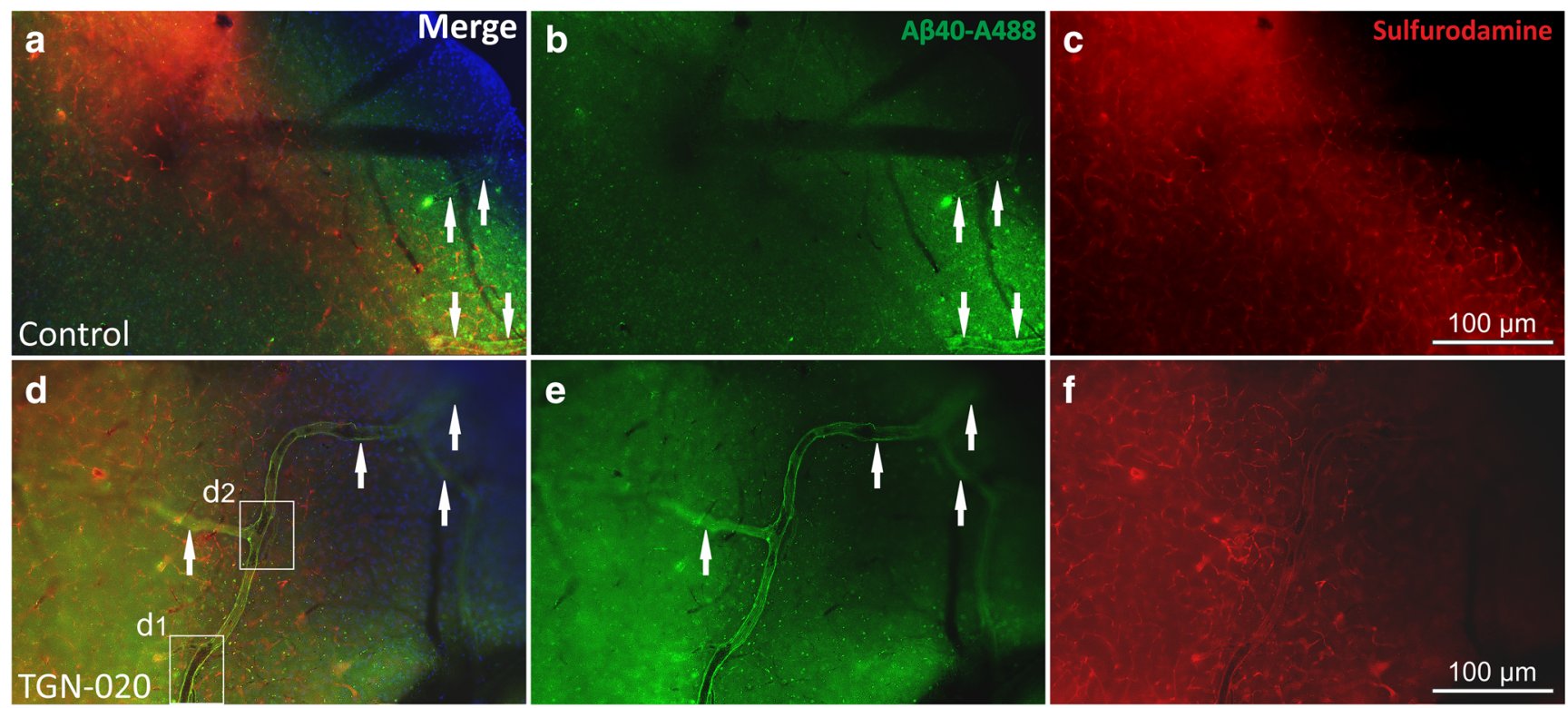
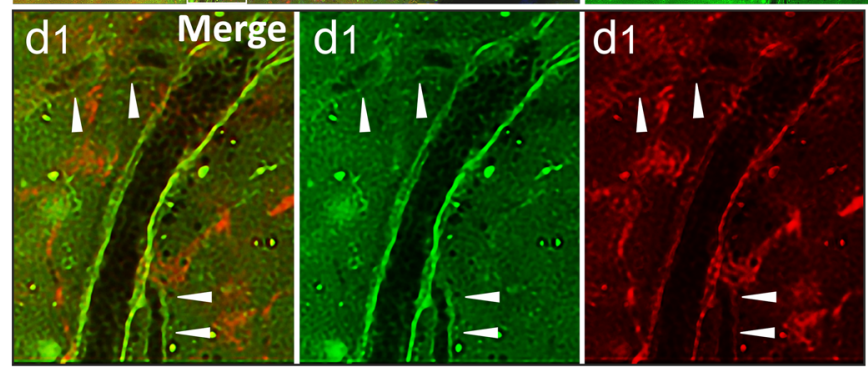

Fig. 3 Ex vivo fluorescence imaging of $A \beta 40$ and Sulfurodamine 101 in control $(\mathbf{a}-\mathbf{c})$ and TGN-020-treated animals $(\mathbf{d}-\mathbf{f}, \mathrm{d} 1, \mathrm{~d} 2$ insets). Colocalization of the two signals is still visible after tissue processing in
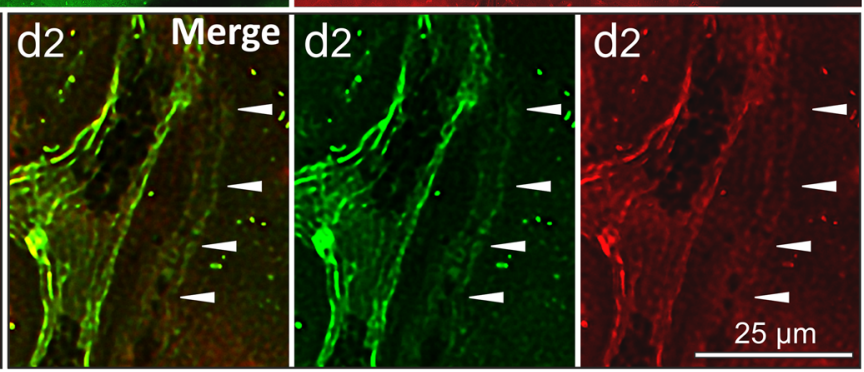

more vessels for treated animals (arrows) and also in more numerous smaller vessels (arrowheads) 
abutting the vessel walls. We further studied if there were any immediate change in the BBB permeability following the high dosage of TGN-020. To this end, a staining for endogenous mouse immunoglobulins was performed, which revealed occasional vascular staining involving the vessel wall itself but also with a diffuse staining pattern in the immediate surrounding neuropil (Fig. 4, a-f). This pattern was present in all cortical and subcortical regions, including the cerebellum. In order to assess putative differences between the two animal groups, we calculated the average diameters of IgG-positive vessels for control and TGN-020-treated animals, as well as the average number of stained vessels. Although the average diameter of IgG-positive blood vessels tended to be higher in all brain areas for control animals, this difference attained statistical significance only for the cerebellum (15.452 \pm $3.326 \mu \mathrm{m}$ vs $24.963 \pm 2.210 \mu \mathrm{m}, P=0.0045)$, and from here for all the vessels pooled together $(18.554 \pm 3.255 \mu \mathrm{m}$ vs $24.317 \pm 1.941 \mu \mathrm{m}, P=0.0216$ ) (Fig. $4, \mathrm{~g}$ ). Regarding the number of stained vessels, control animals tended to show higher average values in all analyzed regions, except for basal ganglia, and with a significant difference only for the cortical vessels $(5.632 \pm 1.474$ vs $7.822 \pm 1.078$ vessels $/ \times 20$ objective area, $P=0.0415$ ) (Fig. 4 , h).

\section{TGN-020 Does Not Induce Any Significant Variation in the Thickness of the Vascular Basement Membranes}

Next, we assessed the thickness of the vascular BM on $\times 60$ deconvoluted fluorescence images captured for laminin and GFAP double stainings (Fig. 5, a-d). For all anatomical regions, and for both animal groups, there was a good homogeneity of BM thickness with basically no significant difference or even tendency, suggesting no major direct effect of TGN020 (Fig. 5, e). Also, the GFAP staining did not show any differences in astrocytic density or preponderance for both animal groups. Lastly, we assessed whether there was a

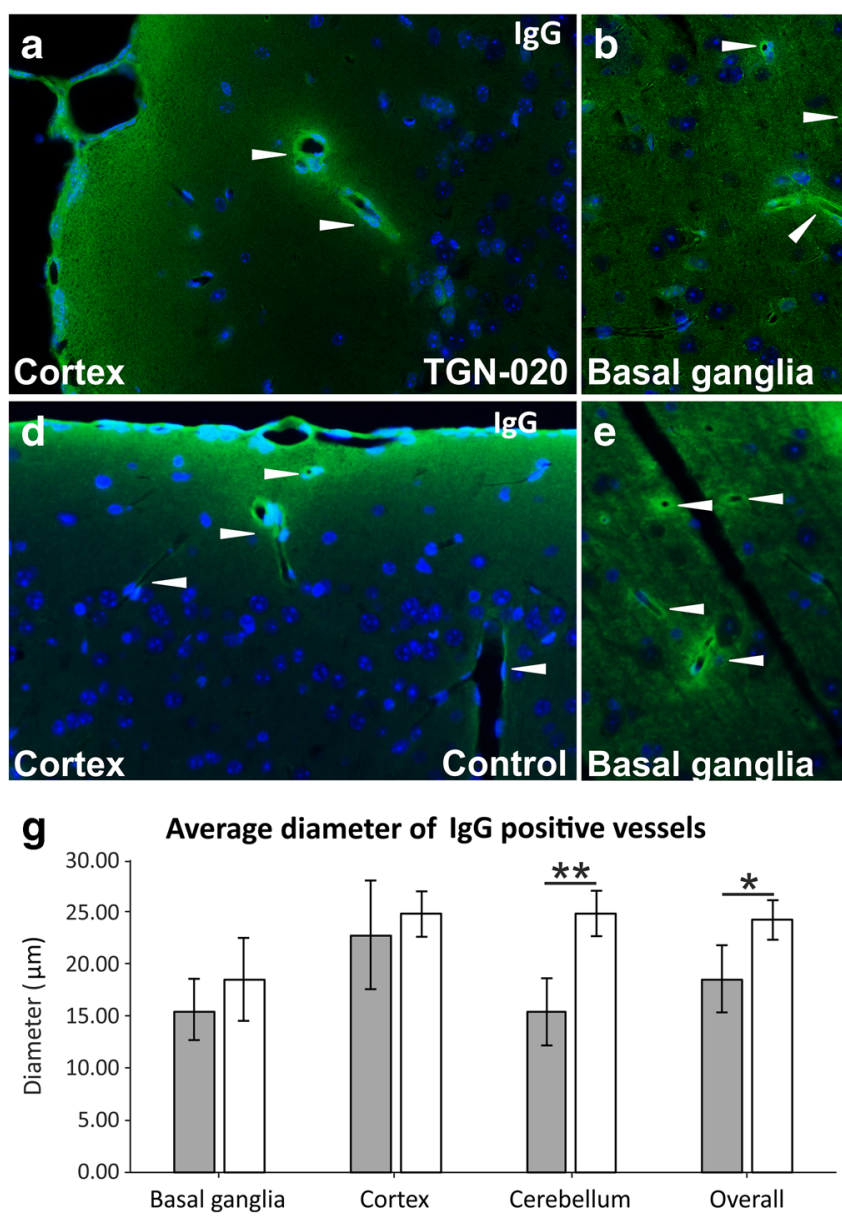

Fig. 4 Post-fixed tissues immunostained for endogenous murine immunoglobulins (a-f) show only a regional decrease in IgG permeability for TGN-020-treated animals, both as the average diameter of positive vessels (g) and as the number of positive vessels (h). The

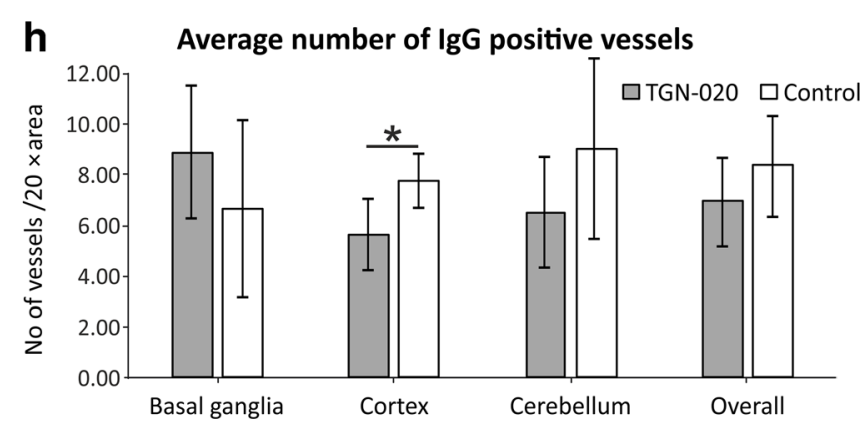

average value per animal was considered for analysis. Mean $\pm \mathrm{SD}$; ${ }^{*} P<0.05,{ }^{* *} P<0.01$. $N=5$ animals for the TGN-020 group and 3 animals for the control group 

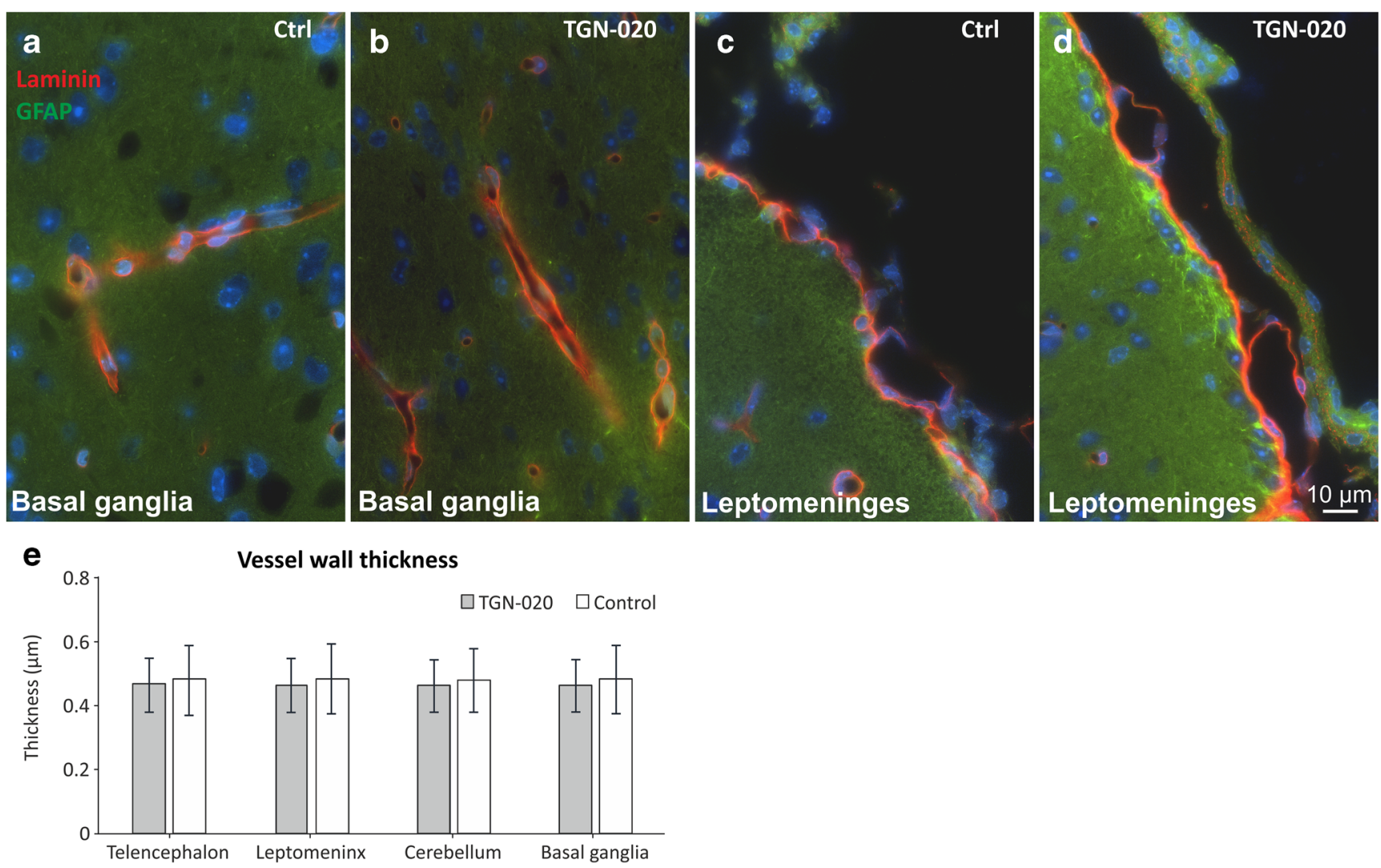

Fig. 5 Post-fixed tissues immunostained for laminin and GFAP show no obvious differences between the basement membranes' thickness utilizing light microscopy, nor any gliotic reaction, between the control

correlation between the vessel diameter and its measured BM thickness. Descriptive analysis revealed that in control animals, the blood vessel diameters showed a modest correlation with the wall thickness $[r(374)=0.262, P<0.001]$, while this correlation was slightly lower in TGN-020-treated animals $[r(414)=0.113, P=0.011]$.

\section{No Ultrastructural BBB Changes After TGN-020 Treatment}

Qualitative analysis by TEM revealed no structural differences in the appearance of capillaries from grey matter $(n=$ 60) of TGN-020-treated C57BL6 mice, compared with the same number of cortical vessels from control C57BL6 mice (Fig. 6, a-c). Specifically, a univariate analysis of variance (ANOVA) for TGN-020-treated and control animals revealed no significant differences in the percentage surface area of the vessel walls occupied by the endothelium $(61.11 \%$ vs. $62.01 \%, P=0.494)$, basement membrane $(25.84 \%$ vs. $25.83 \%, P=0.987)$, or intramural cells $(13.05 \%$ vs. $12.16 \%$, $P=0.492$ ). These data suggest that a single massive dose of TGN-020 does not alter the ultrastructural structure of blood vessels.

and TGN-020-treated animals (a-e). The average value per animal was considered for analysis. Mean $\pm \mathrm{SD}$. $N=5$ animals for the TGN-020 group and 3 animals for the control group

\section{Discussion}

AQPs form highly conserved water membrane channels in most living organisms, controlling osmotic-driven water movement around the cellular membranes in bacteria, plants, and mammals [43]. In humans, 13 distinct AQPs have been described, and 3 exist in the human CNS: AQP4, AQP1, and AQP9 [44, 45]. AQP1 has been described in the brain classically in the epithelia of the choroid plexus, at low levels in the endothelia, and also in the astrocytic membranes, where most of it was colocalized with AQP4 [44, 46, 47], while AQP9 seems to be restricted to substantia nigra [48].

To date, numerous $A \beta$ clearing mechanisms have been described, all overlapping to different extents depending on their histological relationships to local cellular and vascular elements, but with unknown exact relative contribution towards the catabolism of total $A \beta$ bulk and its subspecies. Intracerebral injection of different $A \beta$ isoforms revealed that these enzymatic pathways act mostly on $A \beta 42$ species, with the main enzyme, nepriliysin, being incapable of degrading A $\beta 40$ [49]. As blood vessels collect most of the metabolic waste in any organ, these have also been implicated in several mechanisms of $A \beta$ clearance. A trans-endothelial bi- 

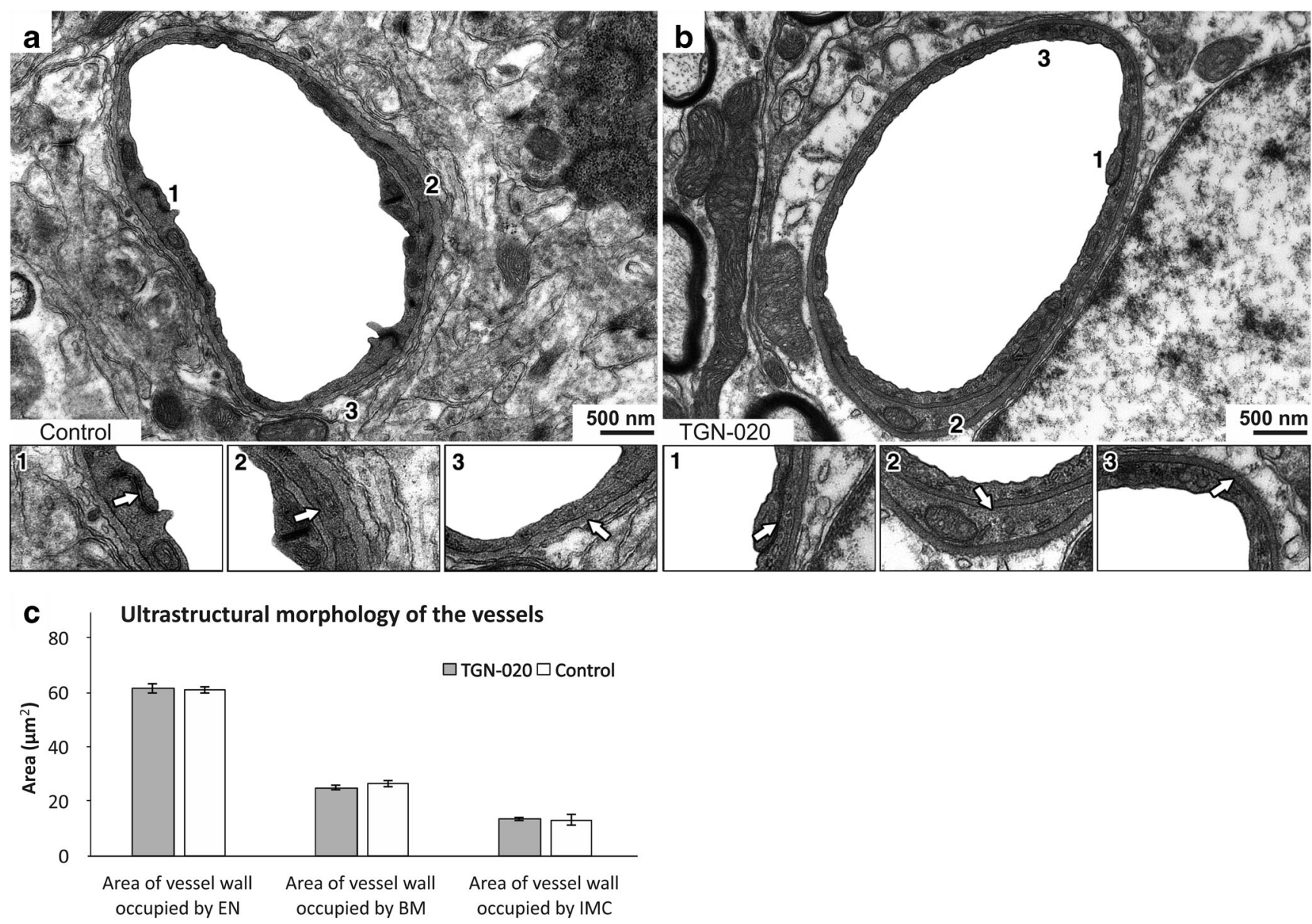

Fig. 6 Inhibition of AQP4 by TGN-020 does not alter the structural appearance of the capillary vascular wall in the grey matter. There was no difference in the ultrastructure of cerebral capillaries from mice treated with TGN-020 (b) when compared with control mice (a). Endothelial

tight junctions ( $\mathrm{a} 1$ and $\mathrm{b} 1$ ), intramural cells ( $\mathrm{a} 2$ and $\mathrm{b} 2$ ), and basement membranes ( $\mathrm{a} 3$ and $\mathrm{b} 3$ ) appeared normal. The average value per animal was considered for analysis. Mean $\pm \mathrm{SD} . N=3$ animals each of the control and TGN-020 groups

directional pathway has been showed to be mediated by the low-density lipoprotein receptor-related protein (LRP) [50] and the receptor for non-enzymatic glycoxidation (RAGE) [51], with both transporters being reported again to be mediating mostly $\mathrm{A} \beta 40$ across the $\mathrm{BBB}$. Besides trans-endothelial transport, a complex "glymphatic" pathway has been introduced to describe the fluid flow out of the brain [52]. Thus, the CSF flows in brain following arterial pulsations, between the basement membrane of the vascular smooth muscle cells and pia mater (Virchow-Robin perivascular space) and is transported across the astrocytic perivascular end-feet to enter interstitial fluid (ISF) of the neuropil. ISF then drains back into the CSF, either along the Virchow-Robin perivascular space or along the vascular basement membranes between the smooth muscle cells and the endothelial cells, but in both cases, it needs to cross through the astrocytic end-feet [31]. In the astrocyte end-feet, AQP4 is the main water channel that drives the bidirectional fluid flux around the bleed vessels [53, 54]. We have previously shown that a single administration of the TGN-020 AQP4 inhibitor on an animal model of ischemic stroke reduces brain cytotoxic oedema by limiting the plasma influx into the parenchyma, and that this effect is associated with thicker vascular basement membranes in ischemic animals treated with TGN-020 [27]. Moreover, there was a clearcut colocalization of the vascular BM's laminin with endogenous murine albumin in the walls of the vessels of these animals, this being a first direct proof that AQP4 inhibition decreases fluid passage around BBB at the level of the outer vascular basement membranes [27]. More recent data utilizing the AQP4 facilitator TGN-073 showed an increased fluid turnover at the level of the BBB, promoting circulation and clearance of the interstitial fluid along the BBB [55]. Also, the observation that intraparenchymal injection of ovalalbumin and dextran also leads to their drainage alongside the vascular basement membranes [56] consolidates this route as a general fluid drainage pathway, not specific but essential for the clearance of soluble $\mathrm{A} \beta$ pool.

In the present study, we have showed for the first time that AQP4 inhibition directly decreases soluble amyloid $A \beta$ drainage through the intramural vascular pathways, suggesting that 
its downregulation at the level of the perivascular astrocytic end-feet, age-related or otherwise, would greatly contribute to the accumulation of $A \beta$ in the brains of LOAD patients. Indeed, a number of astrocytic changes have been described in $\mathrm{AD}$ mouse models and human pathology, like detachment of astrocyte end-feet from the BBB, reduction of end-feet metabolism including loss of astrocytic glucose transporter 1 and of AQP4, and an overall impaired perivascular drainage of solutes $[30,57,58]$. Our experimental setup showed significant differences in $A \beta$ vascular intramural retention between the TGN-020-treated/control animals, and this is despite the fact that surgically opening the skull reduces arterial pulsations and glymphatic flow [59]. Our in vivo results showed that for both inhibitor dosages, fluorescent $\mathrm{A} \beta$ showed a tendency to accumulate mostly in smaller diameter vessels for TGN-020-treated animals compared with the control group $(P=0.066)$. As the BBB per se exists only at the level of the capillaries, and AQP4 is mostly expressed in the perivascular glia limitans and is polarized towards the vascular basement membranes, it is conceivable that these sites are also the most susceptible of being affected by TGN-020. In line with our findings, tracer experiments and two-photon microscopy imaging on mice lacking AQP4 showed a 70\% reduction in clearance of the interstitial fluid along the paravenous drainage pathways, suggesting that astrocyte end-feet is responsible for gating these clearance pathways [60]. This study [60] also assessed the paravascular drainage of $A \beta 40$, although the injection was done in striatum, and assessment was on postmortem vibratome sections. It showed that $\mathrm{A} \beta 40$ was cleared mainly along these pathways in wild-type animals, but in AQP4 knockouts, this drainage was abolished. Although the histology of the arteries in the basal ganglia is slightly different from the cortical arteries, as the former are coated by not one, but two distinct layers of leptomeninges [61], the diffusion principles that apply should be the same as for the cortical vessels. Moreover, AQP4 null mice crossbred with APP/PS1 mice not only show an increase in the total $A \beta$ disposition in their brains compared with APP/PS1 animals but also an increase in the vascular-deposited A $\beta$ (CAA) [62].

Also, we have showed here that the single massive dose of TGN-020 did not induce any detectable microscopical and ultrastructural changes at the level of the blood vessels or their basement membranes, and only to regional differences towards their permeability for endogenous murine immunoglobulins. Despite the fact the BBB comprises a nonfenestrated layer of endothelial cells bound by tight junctions, on a continuous endothelial basement membrane, its impermeability to serum components is not absolute. Under normal conditions, intravenous administration of human IgG in mice revealed that a fraction of the perfusate is able to cross the BBB without inflammation or without causing leakage [63]. In this direction, a variety of mechanisms have been described that might be able to facilitate the access of $\operatorname{IgG}$ in the parenchyma through the blood vessel wall, like for example binding to the neonatal $\mathrm{Fc}$ receptor ( $\mathrm{FcRn}$ ) [64], the LRP-1 [65], transferrin, or insulin receptors [66]. After adhesion, mechanisms like transcytosis and lysosomal degradation have been described to be involved in maintaining an equilibrium in the permeability/impermeability balance, and in fact impaired lysosomal degradation has been showed to be followed by $\operatorname{IgG}$ accumulation in the basement membranes [67]. Altogether, a combination of enhanced vascular permeability due to hypoxic conditions during animal euthanasia, together with the blockade of fluid at the basement membrane-glia limitans interface in TGN-020-treated animals, might explain the increased overall vascular permeability for endogenous IgG in control animals compared with the treated group. It can very well be that the high sensibility of cerebellum to hypoxia, as compared with the rest of the brain [68], together with the more complex anatomy of the vessels in the basal ganglia, surrounded by two distinct layers of leptomeninges separated by a perivascular space [61], could explain the differences observed in cerebellum and basal ganglia in our experiment. Vessel wall thickness was not deemed significantly different between control and TGN-020 animal groups, and there were only low correlation values between the diameters and wall thickness.

A massive TGN-020 administration is not accompanied by detectable functional and morphological changes at the level of the brain or other organs, or by any changes in the AQP4 expression patterns, but with immediate reduction of perivascular fluid exchange and of cytotoxic oedema [26, 27, 69]. Given the fact that PET-CT analysis of the presence of [11C]TGN-020 in the human brain revealed a first pass-effect within the first $10 \mathrm{~min}$, followed by plateau levels for the brain parenchyma in the frame time of 15-60 min post-injection [69], all our experimental approaches (i.e. in vivo, ex vivo, and EM) fall within the same window of comparable functional and morphological changes. The advantage of pharmacological transient inhibition versus gene deletion is that for short period of time, compensatory mechanisms, like the coexistence of AQP1 in the brain, might temporarily take over for AQP4 loss, while AQP4 null animals have been reported to exhibit deficits of membrane potential formation in retinal Müller cells, impaired hearing, and memory consolidation [70-72]. The fact that AQP4 null animals show subtle metabolic changes, and putatively some other nonexplored deficits, makes our experiment the most direct proof of the relationship between AQP4 inhibition and increased A $\beta$ burden in the CNS and in the perivascular sector.

Although our work is a continuation of previous studies that have already shown that soluble $A \beta$ injected into the brain parenchyma is drained according to the diffusion gradients through the capillary basement membranes, and within the basement membranes of the tunica media of cerebral arteries, but not associated with the veins $[31,56]$, the major drawback of the present study was that we could not 
differentiate in vivo the arterial from the venous sector, thus not being able to rule out the paravascular drainage pathways. However, to our knowledge, this is the first study that utilizes a transient AQP4 inhibition to observe the immediate in vivo behavior of soluble and diffusible $A \beta 40$ in relationship to blood vessels.

Interestingly, $A \beta$ accumulation in our in vivo experiment tended to occur especially in smaller diameter vessels after AQP4 inhibition, and IgG infiltration on fixed tissue was also identified in smaller diameter vessels. Both point to the fact that the first nidi of $A \beta$ during plaque formation occurs in the BBB associated with smaller vessels, where the ISF drains directly from within the parenchyma [73]. CAA can be present without concurrent $\mathrm{AD}$ neuropathology; however, it has been showed to be present in up to $90 \%$ of the AD cases [74]. Moreover, not all CAA, but capillary CAA and small vessel pathology (arteriosclerosis), seems to be associated with allocortical microinfarcts and cognitive decline in $\mathrm{AD}$ patients $[75,76]$, so that it can be that $A \beta$ disposition in the small vessels represents the first subtle change that precedes plaque formation that initiates the pathological/cognitive decline.

\section{Conclusion}

This is the first direct proof that transient AQP4 inhibition rapidly reduces the intramural vascular drainage of the ISF from the brain, with a direct effect towards favoring the disposition of amyloid $A \beta$ in the blood vessel walls. Taken together with the age-associated small vessel disease that occurs in $\mathrm{AD}$ patients, AQP4 function assessment and facilitation might be a good prognostic or treatment candidate in these patients.

Acknowledgements TEM was performed by Matt Macgregor Sharp, University of Southampton.

Authors' Contributions DP, BC, MC and SKS designed the study, supervised the experiments, and wrote the manuscript. DP designed and printed the injection micropump. $\mathrm{BC}, \mathrm{TAB}$, and $\mathrm{DP}$ performed in vivo $A \beta 40$ injections and data analysis. GCR, ML, SKS, and DP processed the tissue and performed immunohistochemistry, image grabbing and processing, and histology data analysis. All authors read and approved the final version of the manuscript.

Funding Information This work was financially supported by the CNFIS-FDI-2020-0115 to GCR.

Data Availability All raw data is available from the corresponding authors upon reasonable request.

\section{Compliance with Ethical Standards}

Conflict of Interest The authors declare that they have no competing interests.
Ethics Approval The study was approved by the local Ethics Committee of the University of Medicine and Pharmacy of Craiova, Romania (91/13.09.2018)

Consent to Participate Not applicable.

Consent for Publication Not applicable.

Open Access This article is licensed under a Creative Commons Attribution 4.0 International License, which permits use, sharing, adaptation, distribution and reproduction in any medium or format, as long as you give appropriate credit to the original author(s) and the source, provide a link to the Creative Commons licence, and indicate if changes were made. The images or other third party material in this article are included in the article's Creative Commons licence, unless indicated otherwise in a credit line to the material. If material is not included in the article's Creative Commons licence and your intended use is not permitted by statutory regulation or exceeds the permitted use, you will need to obtain permission directly from the copyright holder. To view a copy of this licence, visit http://creativecommons.org/licenses/by/4.0/.

\section{References}

1. Hardy J, Selkoe DJ (2002) The amyloid hypothesis of Alzheimer's disease: progress and problems on the road to therapeutics. Science 297(5580):353-356. https://doi.org/10.1126/science.1072994

2. Zlokovic BV (2011) Neurovascular pathways to neurodegeneration in Alzheimer's disease and other disorders. Nat Rev Neurosci 12(12):723-738. https://doi.org/10.1038/nrn3114

3. Piaceri I, Nacmias B, Sorbi S (2013) Genetics of familial and sporadic Alzheimer's disease. Front Biosci (Elite Ed) 5:167-177

4. Dorszewska J, Prendecki M, Oczkowska A, Dezor M, Kozubski W (2016) Molecular basis of familial and sporadic Alzheimer's disease. Curr Alzheimer Res 13(9):952-963. https://doi.org/10.2174/ 1567205013666160314150501

5. Ritchie K, Carriere I, Ritchie CW, Berr C, Artero S, Ancelin ML (2010) Designing prevention programmes to reduce incidence of dementia: prospective cohort study of modifiable risk factors. BMJ (Clinical research ed) 341:c3885. https://doi.org/10.1136/bmj. c3885

6. Norton S, Matthews FE, Barnes DE, Yaffe K, Brayne C (2014) Potential for primary prevention of Alzheimer's disease: an analysis of population-based data. Lancet Neurol 13(8):788-794. https:// doi.org/10.1016/s1474-4422(14)70136-x

7. Ritchie K, Ritchie CW, Yaffe K, Skoog I, Scarmeas N (2015) Is late-onset Alzheimer's disease really a disease of midlife? In: Alzheimers dement (NY) 1(2): 122-130. https://doi.org/10.1016/j. trci.2015.06.004

8. Lin H, Bhatia R, Lal R (2001) Amyloid beta protein forms ion channels: implications for Alzheimer's disease pathophysiology. FASEB J 15(13):2433-2444. https://doi.org/10.1096/fj.010377com

9. Rosales-Corral S, Tan DX, Reiter RJ, Valdivia-Velazquez M, Acosta-Martinez JP, Ortiz GG (2004) Kinetics of the neuroinflammation-oxidative stress correlation in rat brain following the injection of fibrillar amyloid-beta onto the hippocampus in vivo. J Neuroimmunol 150(1-2):20-28. https://doi.org/10. 1016/j.jneuroim.2004.01.005

10. Carrillo-Mora P, Luna R, Colin-Barenque L (2014) Amyloid beta: multiple mechanisms of toxicity and only some protective effects? Oxidative Med Cell Longev 2014:795375-795315. https://doi.org/ $10.1155 / 2014 / 795375$ 
11. Kontush A, Berndt C, Weber W, Akopyan V, Arlt S, Schippling S, Beisiegel U (2001) Amyloid-beta is an antioxidant for lipoproteins in cerebrospinal fluid and plasma. Free Radic Biol Med 30(1):119128. https://doi.org/10.1016/s0891-5849(00)00458-5

12. Hureau C, Faller P (2009) Abeta-mediated ROS production by $\mathrm{Cu}$ ions: structural insights, mechanisms and relevance to Alzheimer's disease. Biochimie 91(10):1212-1217. https://doi.org/10.1016/j. biochi.2009.03.013

13. Danysz W, Parsons CG (2012) Alzheimer's disease, beta-amyloid, glutamate, NMDA receptors and memantine-searching for the connections. Br J Pharmacol 167(2):324-352. https://doi.org/10.1111/ j.1476-5381.2012.02057.x

14. Verdier Y, Penke B (2004) Binding sites of amyloid beta-peptide in cell plasma membrane and implications for Alzheimer's disease. Curr Protein Pept Sci 5(1):19-31. https://doi.org/10.2174/ 1389203043486937

15. Wang J, Dickson DW, Trojanowski JQ, Lee VM (1999) The levels of soluble versus insoluble brain Abeta distinguish Alzheimer's disease from normal and pathologic aging. Exp Neurol 158(2): 328-337. https://doi.org/10.1006/exnr.1999.7085

16. Nicoll JA, Yamada M, Frackowiak J, Mazur-Kolecka B, Weller RO (2004) Cerebral amyloid angiopathy plays a direct role in the pathogenesis of Alzheimer's disease. Pro-CAA position statement. Neurobiol Aging 25(5):589-597; discussion 603-584. https://doi. org/10.1016/j.neurobiolaging.2004.02.003

17. Dickson DW, Crystal H, Mattiace LA, Kress Y, Schwagerl A, Ksiezak-Reding H, Davies P, Yen SH (1989) Diffuse Lewy body disease: light and electron microscopic immunocytochemistry of senile plaques. Acta Neuropathol 78(6):572-584. https://doi.org/ 10.1007/bf00691284

18. Roberts KF, Elbert DL, Kasten TP, Patterson BW, Sigurdson WC, Connors RE, Ovod V, Munsell LY et al (2014) Amyloid-beta efflux from the central nervous system into the plasma. Ann Neurol 76(6): 837-844. https://doi.org/10.1002/ana.24270

19. Kumar-Singh S (2008) Cerebral amyloid angiopathy: pathogenetic mechanisms and link to dense amyloid plaques. Genes Brain Behav 7(Suppl 1):67-82. https://doi.org/10.1111/j.1601-183X.2007. 00380.x

20. Nagelhus EA, Veruki ML, Torp R, Haug FM, Laake JH, Nielsen S, Agre P, Ottersen OP (1998) Aquaporin-4 water channel protein in the rat retina and optic nerve: polarized expression in Muller cells and fibrous astrocytes. J Neurosci 18(7):2506-2519

21. Haj-Yasein NN, Vindedal GF, Eilert-Olsen M, Gundersen GA, Skare O, Laake P, Klungland A, Thoren AE et al (2011) Glialconditional deletion of aquaporin-4 (Aqp4) reduces blood-brain water uptake and confers barrier function on perivascular astrocyte endfeet. Proc Natl Acad Sci U S A 108(43):17815-17820. https:// doi.org/10.1073/pnas.1110655108

22. Manley GT, Fujimura M, Ma T, Noshita N, Filiz F, Bollen AW, Chan P, Verkman AS (2000) Aquaporin-4 deletion in mice reduces brain edema after acute water intoxication and ischemic stroke. NatMed 6(2):159-163. https://doi.org/10.1038/72256

23. Katada R, Akdemir G, Asavapanumas N, Ratelade J, Zhang H, Verkman AS (2014) Greatly improved survival and neuroprotection in aquaporin-4-knockout mice following global cerebral ischemia. FASEB J 28(2):705-714. https://doi.org/10.1096/fj.13231274

24. Bloch O, Papadopoulos MC, Manley GT, Verkman AS (2005) Aquaporin-4 gene deletion in mice increases focal edema associated with staphylococcal brain abscess. J Neurochem 95(1):254-262. https://doi.org/10.1111/j.1471-4159.2005.03362.x

25. Tait MJ, Saadoun S, Bell BA, Verkman AS, Papadopoulos MC (2010) Increased brain edema in aqp4-null mice in an experimental model of subarachnoid hemorrhage. Neuroscience 167(1):60-67. https://doi.org/10.1016/j.neuroscience.2010.01.053
26. Igarashi H, Huber VJ, Tsujita M, Nakada T (2011) Pretreatment with a novel aquaporin 4 inhibitor, TGN-020, significantly reduces ischemic cerebral edema. Neurol Sci 32(1):113-116. https://doi. org/10.1007/s10072-010-0431-1

27. Pirici I, Balsanu TA, Bogdan C, Margaritescu C, Divan T, Vitalie V, Mogoanta L, Pirici D et al (2017) Inhibition of aquaporin-4 improves the outcome of ischaemic stroke and modulates brain paravascular drainage pathways. Int J Mol Sci 19(1). https://doi. org/10.3390/ijms19010046

28. Eidsvaag VA, Enger R, Hansson HA, Eide PK, Nagelhus EA (2017) Human and mouse cortical astrocytes differ in aquaporin-4 polarization toward microvessels. Glia 65(6):964-973. https://doi. org/10.1002/glia.23138

29. Mogoanta L, Ciurea M, Pirici I, Margaritescu C, Simionescu C, Ion DA, Pirici D (2014) Different dynamics of aquaporin 4 and glutamate transporter-1 distribution in the perineuronal and perivascular compartments during ischemic stroke. Brain Pathol 24(5):475-493. https://doi.org/10.1111/bpa.12134

30. Hawkes CA, Hartig W, Kacza J, Schliebs R, Weller RO, Nicoll JA, Carare RO (2011) Perivascular drainage of solutes is impaired in the ageing mouse brain and in the presence of cerebral amyloid angiopathy. Acta Neuropathol 121(4):431-443. https://doi.org/10. 1007/s00401-011-0801-7

31. Morris AW, Sharp MM, Albargothy NJ, Fernandes R, Hawkes CA, Verma A, Weller RO, Carare RO (2016) Vascular basement membranes as pathways for the passage of fluid into and out of the brain. Acta Neuropathol 131(5):725-736. https://doi.org/10.1007/ s00401-016-1555-Z

32. Lan YL, Zhao J, Ma T, Li S (2016) The potential roles of aquaporin 4 in Alzheimer's disease. Mol Neurobiol 53(8):5300-5309. https:// doi.org/10.1007/s12035-015-9446-1

33. Lan YL, Chen JJ, Hu G, Xu J, Xiao M, Li S (2017) Aquaporin 4 ?in astrocytes is a target for therapy in Alzheimer's disease. Curr Pharm Des 23(33):4948-4957. https://doi.org/10.2174/ 1381612823666170714144844

34. Haj-Yasein NN, Vindedal GF, Eilert-Olsen M, Gundersen GA, Skare Ø, Laake P, Klungland A, Thorén AE et al (2011) Glialconditional deletion of aquaporin-4 (Aqp4) reduces blood-brain water uptake and confers barrier function on perivascular astrocyte endfeet. Proc Natl Acad Sci U S A 108(43):17815-17820. https:// doi.org/10.1073/pnas.1110655108

35. Xu Z, Xiao N, Chen Y, Huang H, Marshall C, Gao J, Cai Z, Wu T et al (2015) Deletion of aquaporin-4 in APP/PS1 mice exacerbates brain $A \beta$ accumulation and memory deficits. Mol Neurodegener 10. https://doi.org/10.1186/s13024-015-0056-1

36. Smith AJ, Duan T, Verkman AS (2019) Aquaporin-4 reduces neuropathology in a mouse model of Alzheimer's disease by remodeling peri-plaque astrocyte structure. Acta Neuropathol Commun 7(1):74. https://doi.org/10.1186/s40478-019-0728-0

37. Zlokovic BV, Yamada S, Holtzman D, Ghiso J, Frangione B (2000) Clearance of amyloid beta-peptide from brain: transport or metabolism? Nat Med 6(7):718-719. https://doi.org/10.1038/77397

38. Cupido A, B Catalin, H Steffens, F Kirchhoff (2014) Surgical procedures to study microglial motility in the brain and in the spinal cord by in vivo two-photon laser-scanning microscopy. In: Bakota L, Brandt R. (ed) Laser scanning microscopy and quantitative image analysis of neuronal tissue, vol 87. vol Neuromethods. Humana Press, New York

39. Fenrich KK, Weber P, Hocine M, Zalc M, Rougon G, Debarbieux F (2012) Long-term in vivo imaging of normal and pathological mouse spinal cord with subcellular resolution using implanted glass windows. J Physiol 590(16):3665-3675. https://doi.org/10.1113/ jphysiol.2012.230532

40. Albargothy NJ, Johnston DA, MacGregor-Sharp M, Weller RO, Verma A, Hawkes CA, Carare RO (2018) Convective influx/ glymphatic system: tracers injected into the CSF enter and leave 
the brain along separate periarterial basement membrane pathways. Acta Neuropathol 136(1):139-152. https://doi.org/10.1007/ s00401-018-1862-7

41. Pirici D (2019) 3D printed microinjection syringe pump. http:// www.umfcv.ro/medicina,3d-printed-microinjection-syringe-pumpdisciplina-metodologia-cercetarii-stiintifice. Accessed 05.01.2020 2020

42. Sharp MM, Page A, Morris A, Weller RO, Carare RO (2017) Quantitative assessment of cerebral basement membranes using electron microscopy. Methods Mol Biol 1559:367-375. https:// doi.org/10.1007/978-1-4939-6786-5 25

43. Verkman AS (2013) Aquaporins. Curr Biol 23(2):R52-R55. https://doi.org/10.1016/j.cub.2012.11.025

44. Papadopoulos MC, Verkman AS (2013) Aquaporin water channels in the nervous system. Nat Rev Neurosci 14(4):265-277. https:// doi.org/10.1038/nrn3468

45. Verkman AS, Anderson MO, Papadopoulos MC (2014) Aquaporins: important but elusive drug targets. Nat Rev Drug Discov 13(4):259-277. https://doi.org/10.1038/nrd4226

46. Rosu GC, Pirici I, Grigorie AA, Istrate-Ofiteru AM, Iovan L, Tudorica V, Pirici D (2019) Distribution of aquaporins 1 and 4 in the central nervous system. Curr Health Sci J 45(2):218-226. https://doi.org/10.12865/CHSJ.45.02.14

47. Saadoun S, Papadopoulos MC, Davies DC, Bell BA, Krishna S (2002) Increased aquaporin 1 water channel expression in human brain tumours. Br J Cancer 87(6):621-623. https://doi.org/10.1038/ sj.bjc. 6600512

48. Badaut J, Petit JM, Brunet JF, Magistretti PJ, Charriaut-Marlangue C, Regli L (2004) Distribution of aquaporin 9 in the adult rat brain: preferential expression in catecholaminergic neurons and in glial cells. Neuroscience 128(1):27-38. https://doi.org/10.1016/j. neuroscience.2004.05.042

49. Iwata N, Tsubuki S, Takaki Y, Watanabe K, Sekiguchi M, Hosoki E, Kawashima-Morishima M, Lee HJ et al (2000) Identification of the major Abeta1-42-degrading catabolic pathway in brain parenchyma: suppression leads to biochemical and pathological deposition. Nat Med 6(2):143-150

50. Shibata M, Yamada S, Kumar SR, Calero M, Bading J, Frangione B, Holtzman DM, Miller CA et al (2000) Clearance of Alzheimer's amyloid-ss(1-40) peptide from brain by LDL receptor-related protein-1 at the blood-brain barrier. J Clin Invest 106(12):1489-1499

51. Deane R, Du YS, Submamaryan RK, Larue B, Jovanovic S, Hogg E, Welch D, Manness L et al (2003) RAGE mediates amyloid-beta peptide transport across the blood-brain barrier and accumulation in brain. Nat Med 9(7):907-913

52. Iliff JJ, Lee H, Yu M, Feng T, Logan J, Nedergaard M, Benveniste H (2013) Brain-wide pathway for waste clearance captured by contrast-enhanced MRI. J Clin Invest 123(3):1299-1309. https:// doi.org/10.1172/JCI67677

53. Rash JE, Yasumura T, Hudson CS, Agre P, Nielsen S (1998) Direct immunogold labeling of aquaporin- 4 in square arrays of astrocyte and ependymocyte plasma membranes in rat brain and spinal cord. Proc Natl Acad Sci U S A 95(20):11981-11986

54. Papadopoulos MC, Verkman AS (2007) Aquaporin-4 and brain edema. Pediatr Nephrol 22(6):778-784. https://doi.org/10.1007/ s00467-006-0411-0

55. Huber VJ, Igarashi H, Ueki S, Kwee IL, Nakada T (2018) Aquaporin-4 facilitator TGN-073 promotes interstitial fluid circulation within the blood-brain barrier: [17O]H2O JJVCPE MRI study. Neuroreport 29(9):697-703. https://doi.org/10.1097/WNR. 0000000000000990
56. Carare RO, Bernardes-Silva M, Newman TA, Page AM, Nicoll JA, Perry VH, Weller RO (2008) Solutes, but not cells, drain from the brain parenchyma along basement membranes of capillaries and arteries: significance for cerebral amyloid angiopathy and neuroimmunology. Neuropathol Appl Neurobiol 34(2):131-144. https://doi.org/10.1111/j.1365-2990.2007.00926.x

57. Wilcock DM, Vitek MP, Colton CA (2009) Vascular amyloid alters astrocytic water and potassium channels in mouse models and humans with Alzheimer's disease. Neuroscience 159(3):10551069. https://doi.org/10.1016/j.neuroscience.2009.01.023

58. Merlini M, Meyer EP, Ulmann-Schuler A, Nitsch RM (2011) Vascular beta-amyloid and early astrocyte alterations impair cerebrovascular function and cerebral metabolism in transgenic arcAbeta mice. Acta Neuropathol 122(3):293-311. https://doi.org/ 10.1007/s00401-011-0834-y

59. Plog BA, Lou N, Pierre CA, Cove A, Kenney HM, Hitomi E, Kang H, Iliff JJ et al (2019) When the air hits your brain: decreased arterial pulsatility after craniectomy leading to impaired glymphatic flow. J Neurosurg:1-14. https://doi.org/10.3171/2019.2. JNS182675

60. Iliff JJ, Wang M, Liao Y, Plogg BA, Peng W, Gundersen GA, Benveniste H, Vates GE et al (2012) A paravascular pathway facilitates CSF flow through the brain parenchyma and the clearance of interstitial solutes, including amyloid beta. Sci Transl Med 4(147): 147ra111. https://doi.org/10.1126/scitranslmed.3003748

61. Pollock H, Hutchings M, Weller RO, Zhang ET (1997) Perivascular spaces in the basal ganglia of the human brain: their relationship to lacunes. J Anat 191(Pt 3):337-346. https://doi.org/ 10.1046/j.1469-7580.1997.19130337.x

62. Xu Z, Xiao N, Chen Y, Huang H, Marshall C, Gao J, Cai Z, Wu T et al (2015) Deletion of aquaporin-4 in APP/PS1 mice exacerbates brain Abeta accumulation and memory deficits. Mol Neurodegener 10:58. https://doi.org/10.1186/s13024-015-0056-1

63. St-Amour I, Pare I, Alata W, Coulombe K, Ringuette-Goulet C, Drouin-Ouellet J, Vandal M, Soulet D et al (2013) Brain bioavailability of human intravenous immunoglobulin and its transport through the murine blood-brain barrier. J Cereb Blood Flow Metab 33(12):1983-1992. https://doi.org/10.1038/jcbfm.2013.160

64. Deane R, Sagare A, Hamm K, Parisi M, LaRue B, Guo H, Wu Z, Holtzman DM et al (2005) IgG-assisted age-dependent clearance of Alzheimer's amyloid beta peptide by the blood-brain barrier neonatal Fc receptor. J Neurosci 25(50):11495-11503. https://doi.org/ 10.1523/JNEUROSCI.3697-05.2005

65. Proulx DP, Rouleau P, Pare I, Vallieres-Noel MM, Bazin R (2012) Interaction between intravenous immunoglobulin (IVIg) and the low-density lipoprotein receptor-related protein 1: a role for transcytosis across the blood brain barrier? J Neuroimmunol 251(1-2):39-44. https://doi.org/10.1016/j.jneuroim.2012.06.009

66. Paris-Robidas S, Emond V, Tremblay C, Soulet D, Calon F (2011) In vivo labeling of brain capillary endothelial cells after intravenous injection of monoclonal antibodies targeting the transferrin receptor. Mol Pharmacol 80(1):32-39. https://doi.org/10.1124/mol.111. 071027

67. Villasenor R, Ozmen L, Messaddeq N, Gruninger F, Loetscher H, Keller A, Betsholtz C, Freskgard PO et al (2016) Trafficking of endogenous immunoglobulins by endothelial cells at the bloodbrain barrier. Sci Rep 6:25658. https://doi.org/10.1038/srep25658

68. Cervos-Navarro J, Diemer NH (1991) Selective vulnerability in brain hypoxia. Crit Rev Neurobiol 6(3):149-182

69. Suzuki Y, Nakamura Y, Yamada K, Huber VJ, Tsujita M, Nakada $\mathrm{T}$ (2013) Aquaporin-4 positron emission tomography imaging of 
the human brain: first report. J Neuroimaging 23(2):219-223. https://doi.org/10.1111/j.1552-6569.2012.00704.x

70. Li J, Patil RV, Verkman AS (2002) Mildly abnormal retinal function in transgenic mice without Muller cell aquaporin-4 water channels. Invest Ophthalmol Vis Sci 43(2):573-579

71. Li J, Verkman AS (2001) Impaired hearing in mice lacking aquaporin-4 water channels. J Biol Chem 276(33):31233-31237. https://doi.org/10.1074/jbc.M104368200

72. Fan Y, Liu M, Wu X, Wang F, Ding J, Chen J, Hu G (2013) Aquaporin-4 promotes memory consolidation in Morris water maze. Brain Struct Funct 218(1):39-50. https://doi.org/10.1007/ s00429-011-0373-2

73. Thal DR, Griffin WS, Braak H (2008) Parenchymal and vascular Abeta-deposition and its effects on the degeneration of neurons and cognition in Alzheimer's disease. J Cell Mol Med 12(5B):18481862. https://doi.org/10.1111/j.1582-4934.2008.00411.x

74. Serrano-Pozo A, Frosch MP, Masliah E, Hyman BT (2011) Neuropathological alterations in Alzheimer disease. Cold Spring
Harb Perspect Med 1(1):a006189. https://doi.org/10.1101/ cshperspect.a006189

75. Hecht M, Kramer LM, von Arnim CAF, Otto M, Thal DR (2018) Capillary cerebral amyloid angiopathy in Alzheimer's disease: association with allocortical/hippocampal microinfarcts and cognitive decline. Acta Neuropathol 135(5):681-694. https://doi.org/10. 1007/s00401-018-1834-y

76. Thal DR, Ghebremedhin E, Orantes M, Wiestler OD (2003) Vascular pathology in Alzheimer disease: correlation of cerebral amyloid angiopathy and arteriosclerosis/lipohyalinosis with cognitive decline. J Neuropathol Exp Neurol 62(12):1287-1301. https:// doi.org/10.1093/jnen/62.12.1287

Publisher's Note Springer Nature remains neutral with regard to jurisdictional claims in published maps and institutional affiliations. 